\title{
On the Influence of Thermomechanical Treatments on Shape Memory Alloys
}

\author{
D. Treppmann and E. Hornbogen \\ Ruhr-University Bochum, Institute for Materials, 44780 Bochum, Germany
}

\begin{abstract}
Thermomechanical treatments (TMT) are used to modify the microstructure of austenite or martensite by introducing lattice defects and / or particles of a second phase. The temperature range extends between $T \geq M_{d}$ (pure ausforming) and $\mathrm{T} \leq \mathrm{M}_{\mathrm{f}}$ (pure marforming). In the intermediate range $\left(\mathrm{M}_{\mathrm{f}}<\mathrm{T}<\mathrm{M}_{\mathrm{d}}\right)$ a more complex behaviour is found. TMT are discussed in a systematic manner using NiTi-based and Cu-based alloys as examples. Transformation behaviour and mechanical properties of TM-treated alloys are compared with undeformed ones. The following effects can be observed for thermal transformation cycles: (a1) lowering or raising of transformation temperatures, (a2) widening or decreasing of hysteresis, (a3) induction of multiple step transformation mechanisms, (a4) reduction of martensitic retransformability (e.g. plastic deformation of martensite $=$ marforming). The mechanical properties are also highly affected: (b1) increase in pseudo yield stress, (b2) increase or decrease in shape memory strain, (b3) increase in conventional strength, (b4) increase in elongation at fracture (by hot rolling of austenite = ausforming). It is shown how tailor-made microstructures are obtained, which in turn provide the best bulk properties for specified applications of SMA in engineering.
\end{abstract}

\section{INTRODUCTION}

There are two different kinds of properties which are required for application of shape memory components. Besides the conventional structural properties which can be summarized as strength (tensile stress, conventional yield stress, resistance against crack failure) shape memory alloys have to provide new functional properties for pseudoelastic, pseudoplastic, or two-way effect behaviour (pseudo yield stress, phase transformation characteristics). Usually, an optimum of these two sets of properties (which are not independent of each other) is aspired. Thermomechanical treatments (TMT) provide a way to modify them by introducing certain lattice defects either into austenite ( $\beta$-phase) or martensite $\left(\alpha_{M}\right.$-phase), fig.1. Vacancies, solute atoms, dislocations, grain boundaries, and particles (0- to 3-dimensional lattice defects) will affect nucleation and propagation of diffusionless transformations [1] and raise the conventional strength. From the engineering point of view the control of TMT is important in two aspects: 1) Shaping of semifinished products (metal sheets, tubes, bars). 2) Optimization of microstructure in order to obtain the useful properties. Phase diagrams (T-c) and timetemperature transformation diagrams $(t-T-t)$ define the limits for thermomechanical treatments $[2,3]$. Using NiTi alloys as example to show the principal features, we can distinguish six temperature ranges with qualitatively different behaviour of the materials occuring during TMT (table 1). For TMT, the total range between melting temperatures and the end of diffusionless transformation $\left(\mathrm{M}_{\mathrm{f}}\right)$ is of importance (fig. 2). The upper range is the "pure ausforming" (plastic deformation of thermodynamical stable autenite), the lowest range is designated as "pure

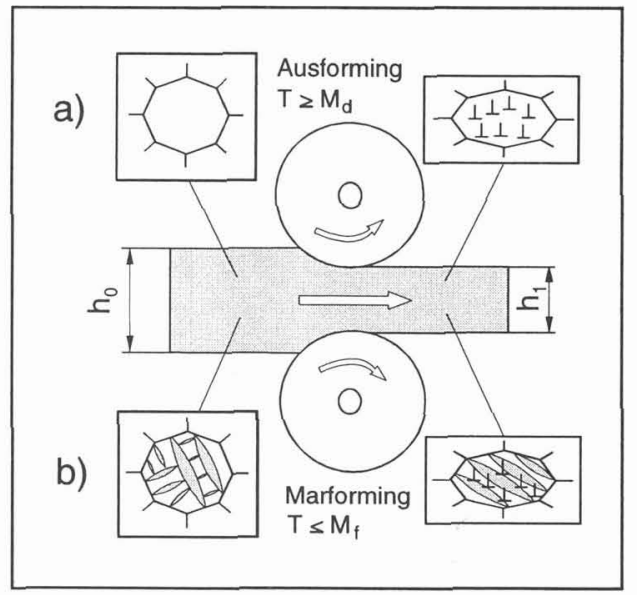

Fig. 1: Schematic presentation of the (a) ausforming and (b) marforming procedure. For $\mathrm{M}_{\mathrm{d}}<\mathrm{T}<\mathrm{M}_{\mathrm{f}}$, mixed deformation is observed. 
marforming" deformation at temperatures below martensite finish (fig. 1). In the intermediate temperature range martensite may form from already plastically deformed austenite (strain induced martensite). We can form stress induced martensite from undeformed austenite and reorientated martensite from already partially transformed microstructure (table 1).

Table 1: Temperature ranges and conceivable solid state reations during TMT. For $T>M_{d}$ mechanical twinning can be observed in NiTi alloys. The induction of R-phase transformation in NiTi-based alloys is possible for lower ausforming temperatures $\left(\mathrm{M}_{\mathrm{d}}<\mathrm{T} \leqslant 450^{\circ} \mathrm{C}\right)$ as well as by intermediate amounts of marforming or mixed deformation.

\begin{tabular}{|c|c|c|}
\hline & $\begin{array}{c}\text { Temperature } \\
\text { range }\end{array}$ & Conceivable solid state reactions during deformation \\
\hline \multirow{2}{*}{$\begin{array}{l}\text { Pure } \\
\text { Ausforming }\end{array}$} & $\mathrm{T}_{1} \geq \mathrm{M}_{\mathrm{d}}$ & Deformation of stable austenite ( $\beta$-phase, fig. 2 ) \\
\hline & $\mathrm{T}_{2} \geq \mathrm{M}_{\mathrm{d}}$ & Deformation of two phases ( $\beta$-phase + precipitates, fig. 2 ) \\
\hline \multirow{3}{*}{$\begin{array}{l}\text { Mixed } \\
\text { Deformation }\end{array}$} & $A_{f}<T_{3}<M_{d}$ & $\begin{array}{l}\text { Formation of martensite from plastically deformed austenite } \\
\text { (strain induced martensite) }\end{array}$ \\
\hline & $\mathrm{M}_{\mathrm{s}}<\mathrm{T}_{4}<\mathrm{T}_{3}$ & $\begin{array}{l}\text { Stress induced martensite from undeformed } \beta \text { and its subsequent plastical } \\
\text { deformation }\end{array}$ \\
\hline & $\mathrm{M}_{\mathrm{f}}<\mathrm{T}_{5} \leq \mathrm{M}_{\mathrm{s}}$ & $\begin{array}{l}\text { Completion of martensitic formation, reorientation of temperature-induced } \\
\text { martensite and its subsequent plastical deformation }\end{array}$ \\
\hline $\begin{array}{c}\text { Pure } \\
\text { Marforming }\end{array}$ & $\mathrm{T}_{6} \leq \mathrm{M}_{\mathrm{f}}$ & $\begin{array}{l}\text { (Pseudo plastic) reorientation of martensite and subsequent plastic deformation } \\
\left(\alpha_{\mathrm{M}} \text {-phase, fig. } 2\right)\end{array}$ \\
\hline
\end{tabular}

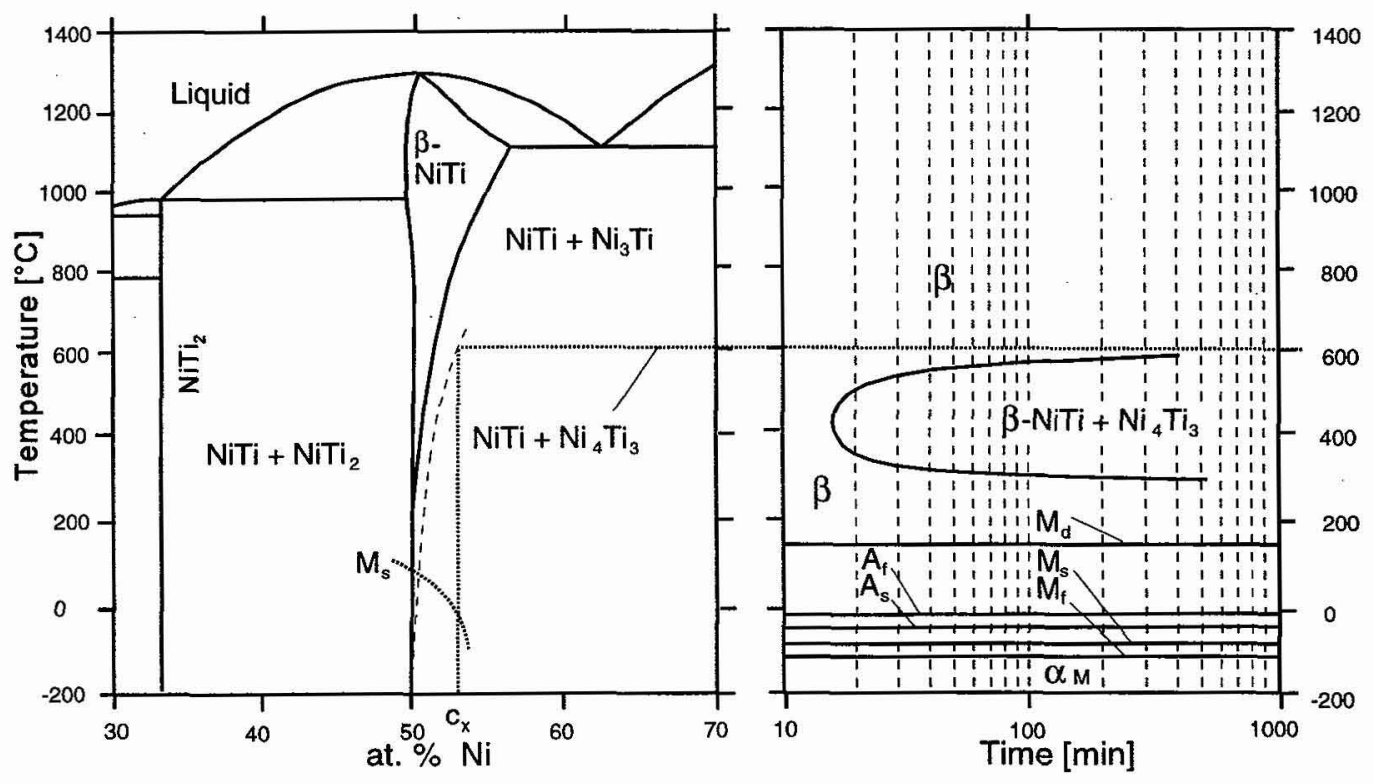

Fig. 2: Semi schematic phase diagram (T-c) and time-temperatures transformation diagram (t-T-t) of NiTi [2, 3]. Plastic deformation of austenite (ausforming) can be obtained at $T \geq M_{\mathrm{d}}$. Plastic deformation of martensite (marforming) can be obtained at $\mathbf{T} \leq \mathbf{M}_{\mathrm{f}}$. Mixed deformation (e. g. plastic deformation of stress induced martensite) is possible in the temperature range $\mathrm{M}_{\mathrm{f}}<\mathrm{T}<\mathrm{M}_{\mathrm{d}}$. The stable precipitation $\mathrm{Ni}_{3} \mathrm{Ti}$ is usually not observed after short annealing treatments. In this range especially metastable $\mathrm{Ni}_{4} \mathrm{Ti}_{3}$ particles are found. 


\section{AUSFORMING}

The purpose of ausforming is (besides shaping) the introduction of lattice defects and consequent work hardening in the structure of austenite. This structure may be ordered up to melting temperature as it is true for NiTi, or an order-disorder transformation occurs which is well known for copper based alloys. The defects in CuZnAl (alloy 1) shown in fig. 3 and 4 affect the phase transformation by lowering the temperature range of martensite and austenite formation (fig. 5a) [4, 5]. This decrease is accompanied by a corresponding increase in pseudo yield stress $\left(R_{p p}\right)$ and tensile stress $\left(R_{m}\right), \underline{f i g} .5 b$. An increasing amount of deformation provides a higher dislocation density: dislocation networks (fig. 4a) and Moirés which might be interpreted as multiple dislocation nets across the thickness of a TEM foil (fig. $4 \mathrm{~b}$ ). The decrease of transformation temperatures is only slight for higher deformation temperatures (due to increasing amount of dynamic recovery and recrystallization). NiTi-based alloys show a similar microstructure after corresponding thermomechanical treatments.
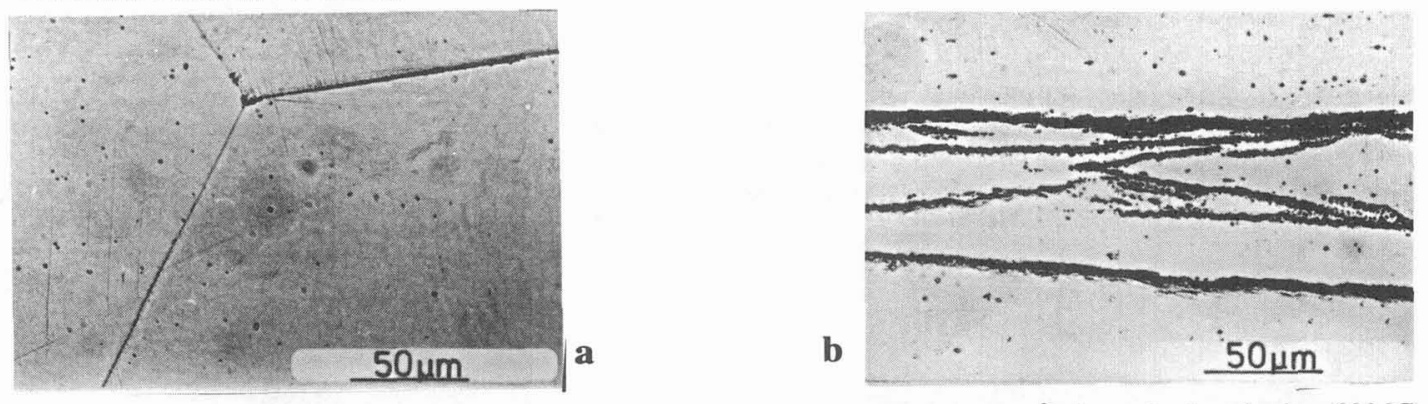

Fig. 3: Changes of microstructure by ausforming of $\mathrm{CuZnAl}$ (alloy 1) [4]. (a) Homogeneous $\beta$-phase after betatization (800 ${ }^{\circ} \mathrm{C}$ ) and water quenching. (b) Elongated grains and serrated grain boundaries after ausforming (with incipient massive transformation to $\alpha$ at grain boundaries, chemical composition remains unaffected), total deformation range $\varphi=\ln \left(h_{0} / h_{1}\right)=1,46$. (LM)
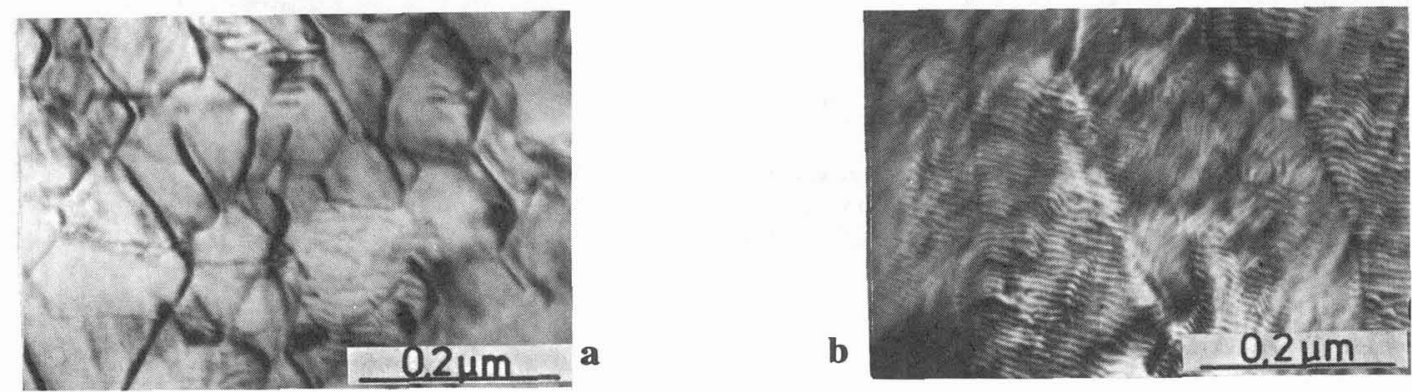

Fig. 4: Formation of dislocation networks by ausforming (at $800^{\circ} \mathrm{C}$ ) of $\mathrm{CuZnAl}$ (alloy 1) [4], total deformation range $\varphi=\ln \left(\mathrm{h}_{0} / \mathrm{h}_{1}\right)=1,46$. (a) Dislocation network. (b) Moiré contrast by overlapping subgrain boundaries. (TEM)

For lower ausforming temperatures the transformation temperatures are shifted considerably. In copper based alloys the range of heterogeneous $\alpha+\beta$ is trespassed and decomposition takes place [5]. Depending on the chemical composition a range of precipitation may be crossed for NiTi-based alloys as well (fig. 2 , $\beta$-NiTi $+\mathrm{Ni}_{4} \mathrm{Ti}_{3}$ ). In NiTi the plastic deformability of $\beta$ decreases, and new twinning phenomena occur with an approximately $45^{\circ}$ orientation to the direction of compressive stress (fig. 6a). The bcc ordered structure is maintained by combined shearing and shuffling [6,7]. For larger amounts of strain, the twins become aligned nearly parallel to rolling direction (fig. 6b) [6]. At very high temperatures deformation twining can disappear because of dynamic recovery [8]. For deformation in the two phase range $\left(\beta-\mathrm{NiTi}+\mathrm{Ni}_{4} \mathrm{Ti}_{3}, \underline{\mathrm{fig}}\right.$. 2) and cold working slightly above $M_{d}$ not only the transformation temperatures, but also the nature of transformation can be changed, and the induction of R-phase in NiTi can be observed. Due to the small necessary shear deformation for the R-phase formation different effects of microstructural features (dislocations) can be expected for R-phase and martensite or austenite transformation. The long range 
austenite $\rightarrow$ martensite transformation is hindered by hardening mechanisms. The same defects remain unaffected by the R-phase or even stimulate its transformation by favourable stress fields (see chapter 6).
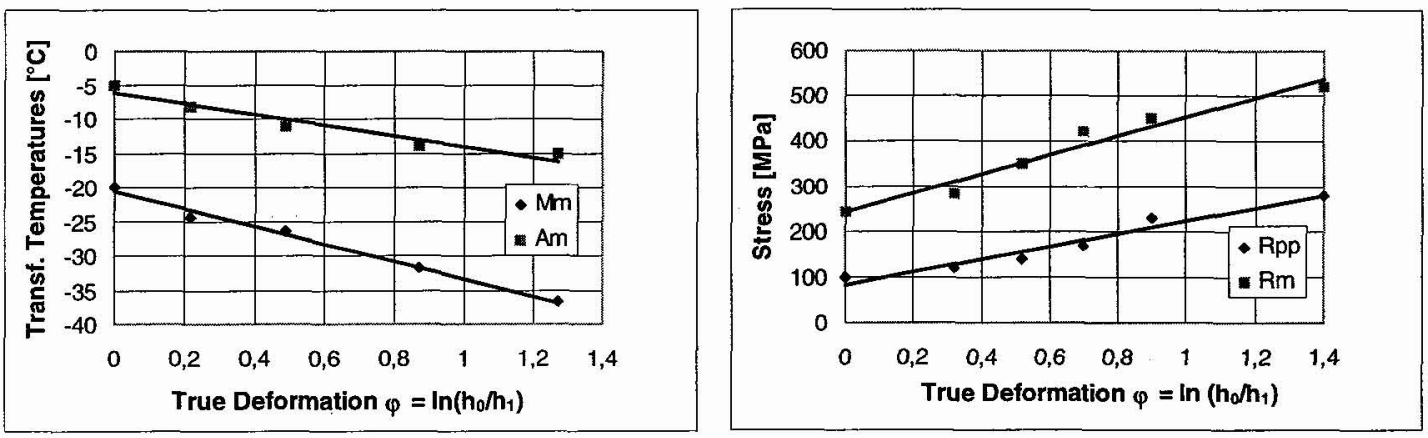

Fig. 5: Effect of ausforming of CuZnAl (alloy 1, deformation temperature $800^{\circ} \mathrm{C}$ ) on phase transformation and stress values. (a) Transformation temperatures determined by DSC measurements as function of true deformation $\varphi . M_{m}$ and $A_{m}$ are the peak maximum temperatures which can be reliably evaluated even after high plastic deformation. (b) Effect of plastic deformation on pseudo yield stress $\left(R_{p p}\right)$ and ultimate tensile stress $\left(R_{m}\right)$. In contrast to conventional materials, the conventional yield stress cannot be determined reliably in SMA due to the fact that microplastic deformations are overlapped by stress induced phase transformation.

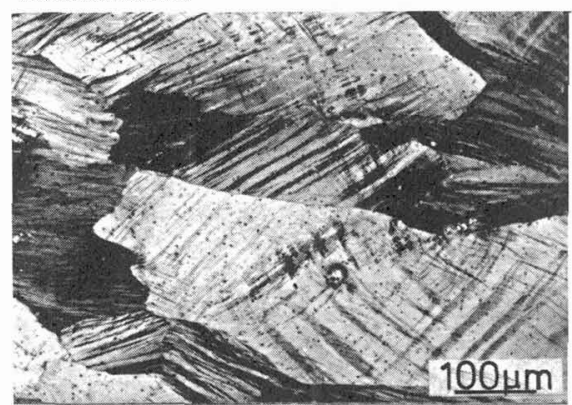

a

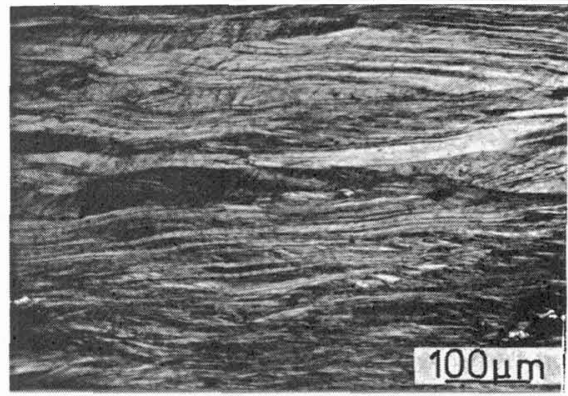

Fig. 6: Ausforming of NiTi (alloy 4), deformation temperature $500^{\circ} \mathrm{C}$ [6]. (a) Mechanical twins with orientation scattering around $45^{\circ}$ to rolling direction, true plastic deformation $\varphi=\ln \left(\mathrm{h}_{0} / \mathrm{h}_{1}\right)=0.32$. (b) Mechanical twinning straightened almost parallel to rolling direction, true plastic deformation $\varphi=\ln \left(\mathrm{h}_{0} / \mathrm{h}_{1}\right)=1.24$. (LM)

\section{MARFORMING}

Plastic deformation after complete thermal formation of martensite leads to the following microscopic changes (true plastic deformation $\varphi=\ln \left(\mathrm{h}_{0} / \mathrm{h}_{1}\right)$ :

$0.00<\varphi_{\mathrm{I}} \preceq 0.08$ : Reorientation of the randomly distributed martensitic domain structure.

$0.05 \preceq \varphi_{\mathrm{II}} \preceq 0.15$ : Localized plastic deformation at twin boundaries or grain boundaries.

$0.10 \preceq \varphi_{\text {III }} \preceq 0.40$ : Transmartensitic plastic deformation (development of dislocations, stacking faults, antiphase boundaries). For higher degrees of deformation, a slight increase in mechanical disordering may be induced.

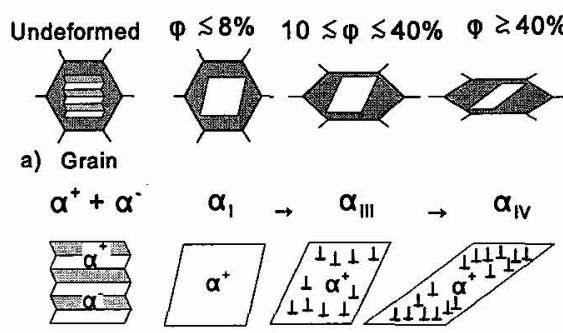

b) Crystall

Fig. 7: Microstructural changes during marforming. (a) Shape change of former $\beta$-grains. (b) Martensitic domains: reorientation of domains, accumulation of dislocations, mechanical disordering. 
Complex homogeneous transmartensitic deformation with increasing disordering and creation of pan-cake grains.

The martensitic transformation may be thermally induced by ambient conditions (alloy 2) or by prior undercooling (alloy 3 ). The amounts of true plastic deformation are approximate values and depend on state of stress as well as on the alloy composition.

The following functional and structural changes become evident for the deformation ranges mentioned above. Generally, the transformation cycles are affected much more by marforming as compared to ausforming at high temperatures.

$\checkmark$ Range I: The transformation temperatures and the strength levels remain almost unaffected. This deformation is necessary for pseudoplasticity (one-way effect).

$\square$ Range I-II: Dislocations introduced by small or intermediate amounts of plastic deformation can create the "effect of first cycle". Defects formed in martensite domain boundaries are able to induce a shift of austenite temperatures to significantly higher values. These defects are able to be annihilated by the first martensite - austenite transformation (reshuffling) and recreate an almost perfect austenite microstructure which possesses a lower austenite temperature during the second transformation cycle (fig. 8,9). The "effect of first cycle" may be used for clamping sleeves in order to avoid an undesired release of shape memory effect during transportation.

$\square$ Range II: Dislocations which are not able to reshuffle and persist in $\beta$ after first transformation cycle originate two-way effect training.

$\checkmark$ Range II-III: Martensite and to a lesser degree austenite temperatures are lowered by cold working (fig. 9). The martensite phase transformation is hindered by dislocations. The Reason for the decrease of austenite transformation temperatures during second and subsequent cycles is the back stress introduced during former transformation into martensite which favours the austenite retransformation (see chapter 6).

$\square$ Range II-III: R-Phase transformation can be induced by intermediate amounts of deformation (fig. 8.9). The dislocations are able to stimulate the R-phase by favourable stress fields.

$\square$ Range IV: For higher amounts of deformation the martensite remains untransformable (fig. 8, 9). The slip in multiple systems may produce progressive disordering. The work hardening ability is reduced. A mechanically induced solid solution whithout order relationship to next neighbours can be created ("dead martensite"). Normally these higher amounts of deformation are not obtained because the alloy breaks before it can acquire such high strains. A practicable method to overcome this difficulty is the simultaneous action

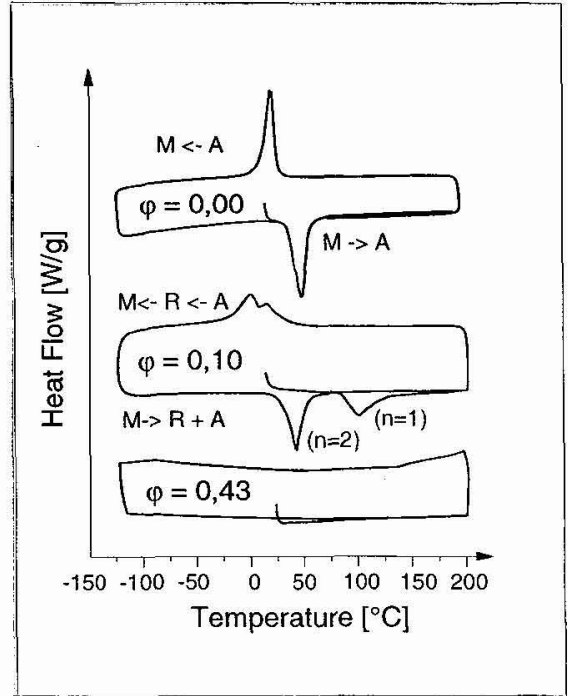

Fig. 8: DSC cycles after marforming of NiTi (alloy 3). True deformation $\varphi=\ln \left(\mathrm{h}_{0} / \mathrm{h}_{1}\right)=0$ (undeformed) up to $\varphi=0.43$ (dead martensite).

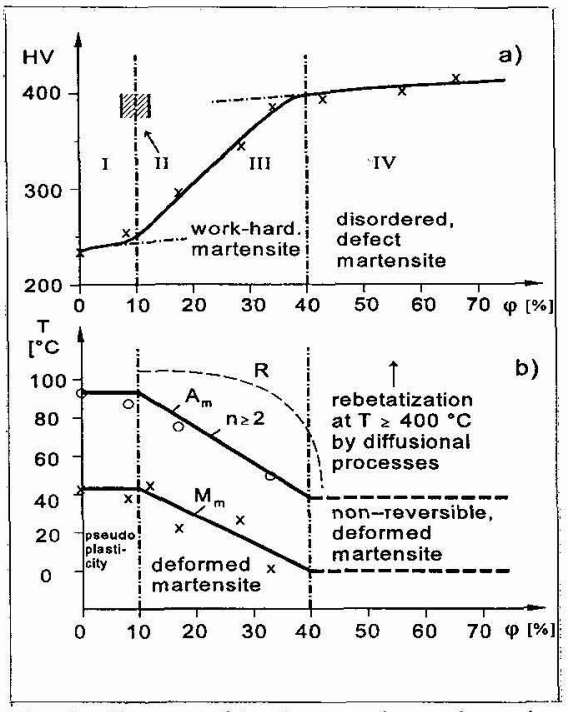

Fig. 9: Changes of hardness and transformation behaviour of NiTi (alloy 2) [9]. True deformation $\varphi=\ln \left(\mathrm{h}_{0} / \mathrm{h}_{1}\right)$. (a) Microhardness results. (I) Reorientation of domains, no work hardening. (II) Effect of first cycle, two-way training range. (III) High work hardening by accumulation of dislocations. (IV) Mechanical disordering by multiple sliding. (b) Peak maximum temperatures determined by DSC ( $n=1$ first, $n \geq 2$ second and following cycles). R-phase preceding martensitic transformation. Dead martensite for $\varphi \geq 40 \%$. 
of hydrostatic stresses (e. g. by encapsulated rolling). Except for small amounts of deformation (effect of first cycle, one-way effect, two-way effect training) marformed conditions usually require reheating / tempering to show again useful properties [10].
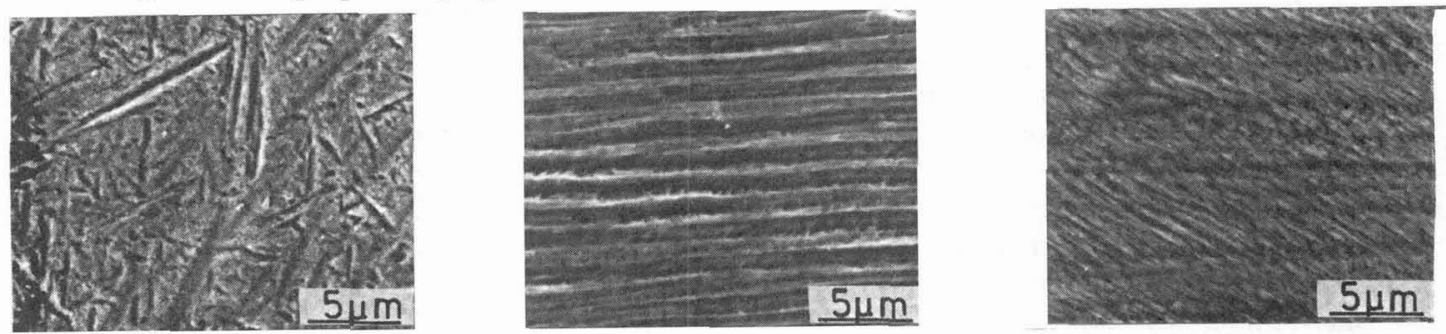

Fig. 10: Scanning electron micrographs (SEM) of marformed NiTi microstructure (alloy 2) [9]. True deformation $\varphi=\ln \left(\mathrm{h}_{0} / \mathrm{h}_{1}\right.$ ). (a) Fractal martensite structure, $\varphi=0$. (b) Reorientation of martenisite domains, $\varphi=0.12$. (c) Multiple plastic shear of oriented domains, $\varphi=0.34$.

\section{MIXED DEFORMATION}

In many engineering SMAs semifinished products have to be treated by cold working at ambient temperature. Due to the transformation characteristics the range of mixed deformation (plastic deformation of formerly stress- or strain-induced martensite, see table 1) is of concern. The microstructure developed in the range of mixed deformation will simultaneously show a complex combination of ausforming (e. $\mathrm{g}$. mechanical twinning of $\beta$-phase in NiTi) and marforming (e. g. transmartensitic plastic deformation of stress induced martensite).

\section{TEMPERING}

For one certain thermomechanical treatment and defined chemical composition a time-temperature-reaction diagram can be prepared. Depending on chemical composition, amount of deformation and thermal activation, the following changes might be observed:

- Reversible and diffusionless martensite $\rightarrow$ austenite transformation (which leads to pseudoplastic deformation $\equiv$ one-way effect behaviour),

- Short range diffusion controlled recovery of dislocations in martensite (or austenite) and partial reordering,

- Diffusion controlled formation of austenite grains within recovered martensitic environment, complete restoration of order and transformability,

- Grain growth in austenite,

Sequential or simultaneous modes of these reactions are also conceivable. Especially alloys with high tendency for precipitation processes enlarge the spectrum of possible reactions. For the true deformation $\varphi_{I V}$ (chapter 3 ) the following solid state reactions might be observed:

$$
\alpha_{N} \rightarrow \alpha_{1} \rightarrow \alpha_{2} \rightarrow(\alpha+\beta)_{3} \rightarrow \beta_{4} \rightarrow \beta_{5}
$$

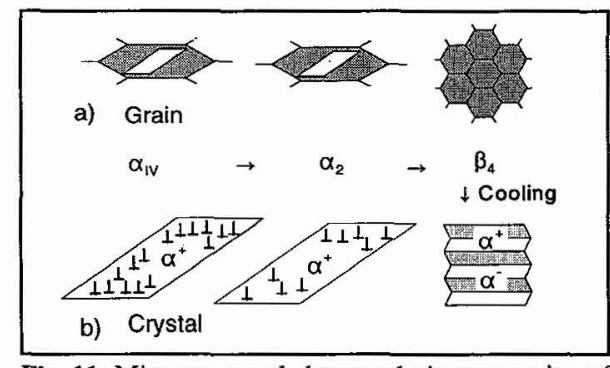

Fig. 11: Microstructural changes during tempering of highly deformed martensite (comp. fig. 7). (a) Recovery and recrystallization of former elongated grains. (b) Recovery and probable reordering of matensite $\left(\alpha_{2}\right)$. Formation of recrystallized $\beta$ which can be carried over into original undeformed martensitic domain structure by subsequent cooling.

Initial state is a highly defect, partially disordered martensite $\alpha_{\text {IV }}$. In range 1, no significant diffusion controlled reactions take place. Still ordered martensite areas may transform diffusionless into austenite (remaining shape memory effect). With increasing thermal activation recovery and precipitation processes are likely to occur in addition to partial restoration of order in the martensitic state $\alpha_{2}$. Finally diffusion controlled, a partial new formation of austenite $\beta$ (range 3 ) and a consequent revival of transformability by recovery of order must take place. A transition to discontinuous 
recrystallization and growth of particles in austenite occurs with increasing annealing temperature and duration $\left(\boldsymbol{\beta}_{4}\right)$. Grain growth and dissolution of particles are the charcteristic reactions in range 5 . The original properties of undeformed, homogeneous material are regained. In conditions of mixed deformation (table 1) which are partially transformed into martensite and afterwards highly plastically deformed, a similar

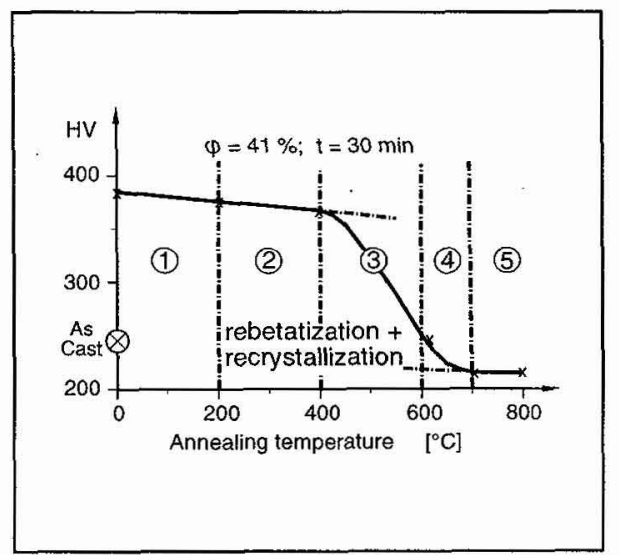

Fig. 12: Five stages of loss of hardness by tempering of highly deformed NiTi martensite (alloy 2) [9]. True deformation $\varphi=0.41$ (cp. fig. 9).

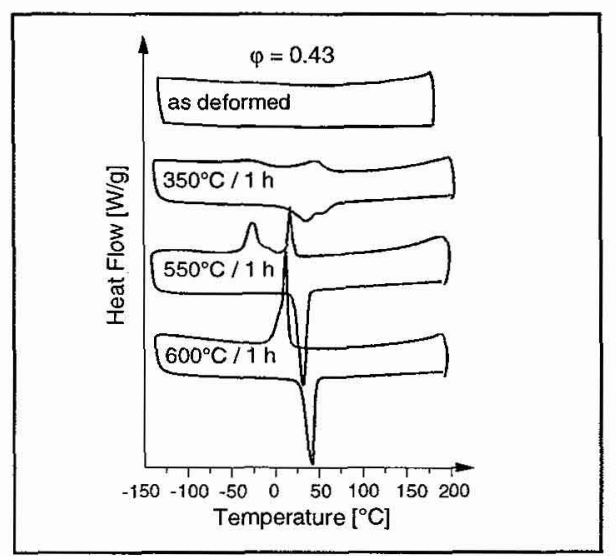

Fig. 13: DSC cycles due to revival of dead martensite by tempering of $\mathrm{NiTi}$ (alloy 3). Initial true deformation $\varphi=\ln \left(\mathrm{h}_{0} / \mathrm{h}_{1}\right)=0.43$ (cp. fig. 8).

annealing behaviour as described in equ. 1 can be expected. The defects introduced by pure ausforming (table 1) should show normal annealing behaviour (recovery, recrystallization, annealing out of twins). In alloys with heterogeneous microstructure (thermal martensite, stress induced martensite and deformed austenite coexisting) a complex behaviour is to be expected. Details of microstructure which can be obtained by tempering of highly deformed martensite have only partially been explored. They may provide a good base for stable shape memory properties.

Table 2: Temperature ranges for annealing of highly deformed martensite

\begin{tabular}{|c|c|c|}
\hline Temperature & Conceivable solid state reactions during tempering & \\
\hline $\mathrm{T}_{\mathrm{l}} \leqslant \mathrm{M}_{\mathrm{f}}$ & Metastable, frozen-in structure of highly deformed martensite & $\alpha_{\mathrm{IV}}=\alpha_{1}$ \\
\hline $\mathrm{M}_{\mathrm{f}} \leqslant \mathrm{T}_{\mathrm{II}} \leqslant \mathrm{M}_{\mathrm{d}}$ & Recovered, possibly partially reordered and decomposed martensite & $\alpha_{2}$ \\
\hline $\mathrm{A}_{\mathrm{s}} \leqslant \mathrm{T}_{\mathrm{IIl}} \leqslant \mathrm{M}_{\mathrm{d}}$ & $\begin{array}{r}\text { nucleation of austenite/ growth of particles in austenite / } \\
\text { combined recovery, recrystallization }\end{array}$ & $(\alpha+\beta)_{3}$ \\
\hline $\mathrm{T}_{\mathrm{IV}} » \mathrm{M}_{\mathrm{d}}$ & Grain growth of austenite and dissolution of particles & $\beta_{4}, \beta_{5}$ \\
\hline
\end{tabular}

Table 3: Characteristics of alloys. Transformation temperatures are given for the solution treated / as betatized state.

\begin{tabular}{|c|c|c|c|c|c|c|c|}
\hline \multirow{2}{*}{ Alloy } & \multicolumn{5}{|c|}{ Nominal chemical composition [at \%] } & \multicolumn{2}{|c|}{$\begin{array}{c}\text { Transformation } \\
\text { temperatures }\left[{ }^{\circ} \mathrm{C}\right]\end{array}$} \\
\hline & $\mathrm{Cu}$ & $\mathbf{Z n}$ & AI & $\mathrm{Ni}$ & $\mathrm{Ti}$ & $\mathbf{M}_{\mathrm{m}}$ & $\mathbf{A}_{\mathbf{m}}$ \\
\hline 1 & 66.8 & 24.4 & 8.8 & - & - & -20 & -5 \\
\hline 2 & - & - & - & 50.0 & 50.0 & 44 & 87 \\
\hline 3 & - & - & - & 50.2 & 49.8 & 12 & 41 \\
\hline 4 & & & & 50.6 & 49.4 & 8 & 38 \\
\hline 5 & - & - & - & 50.8 & 49.2 & -42 & -17 \\
\hline
\end{tabular}




\section{SUMMARY AND CONCLUSIONS}

Thermomechanical treatment (TMT) implies a combination of heat treatment and plastic deformation in either austenite $(\beta)$, martensite $\left(\alpha_{M}\right)$ or heterogeneous microstructures $\left(\alpha_{M}+\beta\right)$. The operation may be conducted sequentially or simultaneously:

Thermal $\rightarrow$ Mechanical: $\quad$ Example: Cold working after tempering.

Mechanical $\rightarrow$ Thermal: $\quad$ Example: Tempering of deformed structure.

Thermal + Mechanical: $\quad$ Example: Hot deformation of austenite.

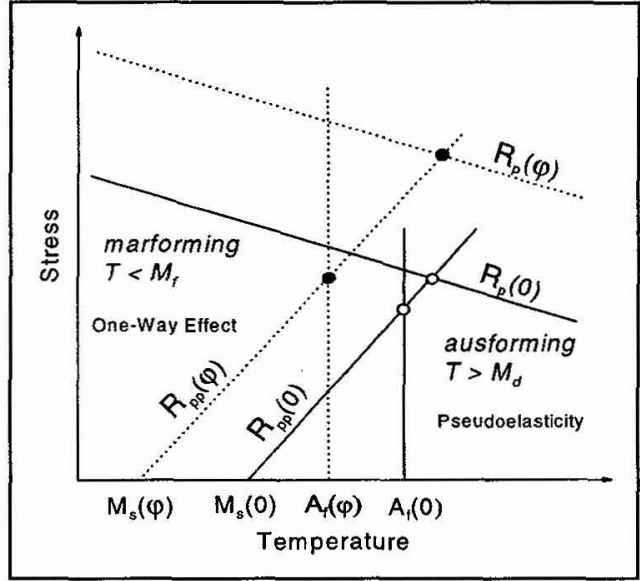

Fig. 14: Stress-temperature dependence of undeformed $(0)$ and deformed ( $\varphi$ ) SMA. Conventional yield stress $R_{p}$ is increased, pseudo yield stress $R_{p p}$ and transformation temperatures $\mathrm{M}_{\mathrm{s}} / \mathrm{A}_{\mathrm{f}}$ are decreased by deformation $\varphi$. Consequently, the range for pseudoelastic behaviour is extended (initial state: between white dots, after deformation between black dots [15]).

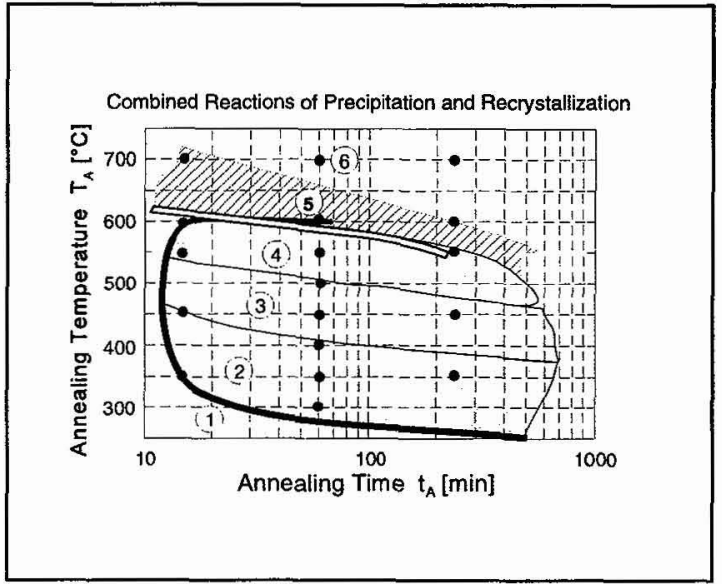

Fig. 15: Time-temperature-reaction diagram for annealing of NiTi (alloy 5) after ausforming (true deformation $\varphi=\ln \left(\mathrm{h}_{0} / \mathrm{h}_{1}\right)$ $=0.22$ ) at ambient temperature $[8,16]$. Each area (1-6) summarizes characteristic microstructure, transformation temperatures, pseudo yield stress, reversibility of one-way or pseudoelastic behaviour as well as typical tensile stress and elongation at fracture data.

The purpose of TMT is the shaping of semifinished products as well as the introduction of lattice defects (dislocations, particles) into $\alpha_{M}$ or $\beta$ in order to modify the bulk properties (fig. 14). Defects introduced into austenite $\beta$ (ausforming) are carried into martensite and lower $M_{s}$. Deformation of $\alpha$ (marforming) is a complex process. It starts with reorientation of the martensite domain structure, continues with deformation of domain boundaries and finally can lead to mechanical disordering by transmartensitic slip. This in turn induces disappearance of the reverse transformability. Deformation of stable $\boldsymbol{\beta}$ (ausforming) usually has to take place at temperatures which are sufficiently high for spontaneous reordering and recovery of defects. Therefore transformability is not lost by this process.

Tempering of as-cast martensitic alloys between $A_{s}$ and $A_{f}$ leads to thermoelastic reformation of $\beta$ (shape memory effect). Small deformations in martensite are able to raise the austenite temperatures for the first retransformation (effect of the first cycle). Revival of highly deformed dead martensite $\alpha_{d}$ requires diffusional processes. Depending on the alloy composition the following sequences are thinkable during tempering:

$\square$ Recovery of defects and probable reordering in martensite $\rightarrow$ nucleation and growth of $\beta \rightarrow$ grain growth of fully transformed $\beta$.

$\square$ Recovery $\rightarrow$ precipitation of metastable phase in $\alpha \rightarrow$ nucleation and growth of $\beta$, precipitation in $\beta \rightarrow$ dissolution of precipitates and grain growth of $\beta$. Precipitates in martensitic state are not yet explored for $\mathrm{NiTi}$, in contrast to CuZn-based SMA [14]. 
Because of disordering below the melting temperature there are differences of hot deformation between $\mathrm{NiTi}-$ and $\mathrm{CuZn}$-based alloys. This leads to differences in the deformation mechanisms and the defect substructure in $\beta$ but only to minor variations in the effetcs on transformation temperatures between the two types of alloys.

There are considerable effects of thermomechanical treatments on R-phase transformation (fig. 16, 17). NiTi alloys which show no R-phase in the as-cast condition, develop a two-step reaction after ausforming at relatively low temperatures. This effect can be ascribed to precipitates and / or dislocation networks that have been formed by the mechano-thermal treatment. Intermediate amounts of marforming have a similar effect. Highly deformed martensite produces strong R-phase effects only in certain stages of tempering. The diffusion controlled reorganization of dislocation networks and / or the precipitation of particles are able to stimulate the rhombohedral phase. For certain kinds of TMT in NiTi even a three step transformation characteristic is observed [1113, 8]. CuZn-based alloys show a two step transformation characteristic to a much lesser degree. The origin of transformation characteristic in $\mathrm{CuZnAl}$ is already investigated [14]. Ausforming at lower temperatures produces particular heterogeneous microstructure.

Ausforming and marforming with or without additional tempering are able to produce a considerable increase of conventional strength (tensile strength, hardness) of the alloys. While ausforming at higher temperatures leaves transformability relatively unaffected, marforming treatments will change the amount and mode of transformation to a great extend. Thus, thermomechanical treatments are suited to shape semi-finished products and simultaneously produce a wide variety of microstructure. TMT may lead to optimized combinations of conventional strength and shape memory properties. A useful method in this context provide time-temperature-reaction diagrams (fig. 15) which are well known from the steels, and should become equally important for SMAs

\section{Acknowledgements}

Thanks are due to Mr. J. Spielfeld (University of Bochum) for helpful discussions, to DFG (German Science Foundation) for supporting the project Ho 325/33-2 and to Volkswagen-Foundation for the support of projekt 170283.

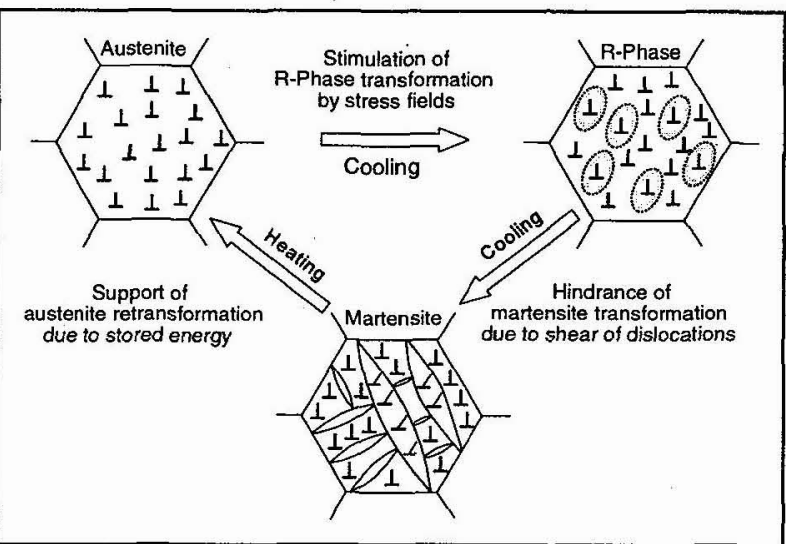

Fig. 16: Effect of dislocations on transformation characteristics in NiTi (schematic). The chemical composition of matrix remains unaffected. transformation and hinder the long range martensitic transformation. Due to the shear of disloctions the austenitic retransformation may be supported by stored elastic energy. The necessary overheating is reduced.

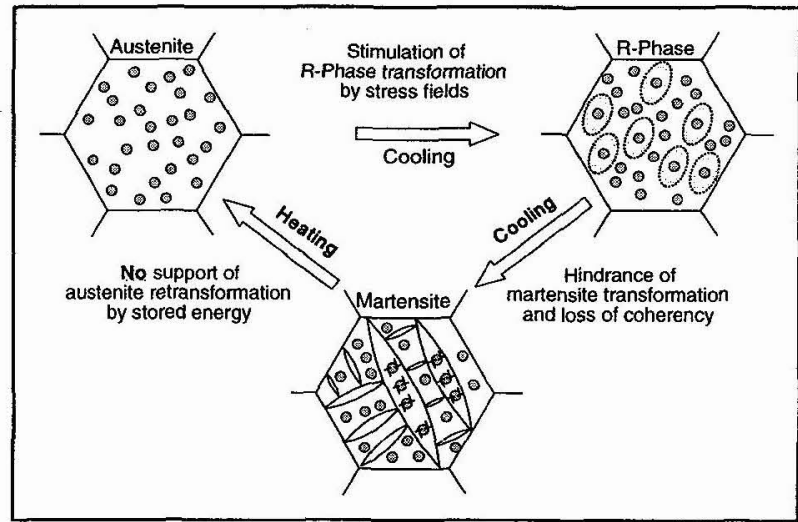

Fig. 17: Effect of particles on transformation characteristics in NiTi (schematic). The nickel content of martix is reduced. Stress fields around precipitates are able to favour the R-phase transformation and impede the long range martensitc transformation. During martensitic transformation particles lose their coherency. The subsequent austenitic retransformation can not be supported by stored elastic energy. Stress fields near to dislocations are able to stimulate the R-phase 


\section{References}

[1] Hornbogen, E., in: S. N. G. Chu et al. (eds.), Micromechanics of Advanced Materials, TMS, Warendale 1995, 307-315

[2] Bellen, R., Kumar, K. C. H., Wollants, P., Z. Metallkde. 87 (1996), 972-978

[3] Nishida, M.,Wayman, C. M., Honma T, Met. Trans. 17A (1986), 1505-1515

[4] Franz, M., Hornbogen, E., Wittkamp, I., in: Kurz, M., Pohl, M. (eds.), Progress in Metallography (in german), DGM, Oberursel, 1995, 311-314

[5] Franz, M., Hornbogen, E., Z. Metallkde. 86 (1995), 31-34

[6] Hornbogen, E., in: Mukherjee, K. et al. (eds.), Int. Conference on Displacive Phase Transformations and their Application in Materials Engineering, Urbana, 1996 - in print -

[7] Moberly, W. J., Proft, J. L., Duerig, T. W., Sinclair, R., Acta metall. mater. 38 (1990), 2601-2612

[8] Treppmann, D., Thermomechanical Treatment of NiTi (in german with english summary and conclusions), VDI-Fortschrittberichte, Reihe 5, Nr. 462, Düsseldorf, VDI-Verlag 1997

[9] Hornbogen, E., Kobus, E., Z. Metallkde. 87 (1996), 442-447

[10] Abujudom, D. N., Thoma, P. E., Fariabi, S.,Mater. Sci. Forum, 56-58 (1990), 565-570

[11] Morawiec, H., Stróż, D., Goryczka, T., Chrobak, D., Scr. Mat. 35 (1996), 485-490

[12] Bataillard, L., Gotthardt, R., J. de Phys. IV, C8, 5 (1995), 647-652

[13] Favier, D., Liu, Y., McCormick, P. G., Scr. Met. Mat. (1993) 28, 669-673

[14] Spielfeld, J., Hornbogen, E., Franz, M., ESOMAT'97, see same proceedings

[15] Lin, H. C, Wu, S. K., Acta metall. mater. 42 (1994), 1623-1630

[16] Treppmann, D., Hornbogen, E., Wurzel, D., J. de Phys. IV, C8, 5 (1995), 569-574 